\title{
Dynamics of the domain structure in non-uniform ferroelectric crystals
}

\author{
K.Matyjasek, R.Rogowski \\ Institute of Physics, Szczecin University of Technology, Al. Piastow 48, 70-310 Szczecin, Poland
}

Received September 4, 2006

This work presents a study of the domain reversal characteristics related to the internal bias field in nonuniform telluric acid ammonium phosphate (TAAP) crystal. We have shown that there is a direct connection between the defective structure of the crystal and stretched exponential polarization relaxation in ferroelectric crystals. The domain switching was studied by means of the nematic liquid crystal decoration technique.

Key words: ferroelectric domains, polarization reversal, internal bias field

PACS: $77.80 . D j, 77.80 . F m, 77.84$

\section{Introduction}

Polarization switching in an external electric field has been intensively studied and is described using classical nucleation and growth concepts of phase transformation (e.g. the KolmogorovAvrami-Ishibashi model [1]). However, relatively less has been reported on the spontaneous reversal of polarization, which occurs in the absence of an external electric field. The existing literature is not consistent regarding their origin and explanation for empirical formulas describing various types of polarization relaxation [2]. In general, retention of polarization in ferroelectrics is related to depolarization field, resulting from incomplete compensation of the polarization charges and internal bias field induced by defects.

In this report, the study of dynamics of the domain structure has been carried out in highly nonuniform TAAP crystal sample. We focus on the investigation of polarization switching dynamics in dc-fields as well as polarization decay after the removal of the electric field. These effects were examined by optical imaging of the domain structure. Microscopic observations provide information on the initial location of the polarization reversal process and its progress as a function of time.

\section{Experimental details}

The TAAP crystal having a chemical formula $\mathrm{Te}(\mathrm{OH})_{6} \cdot 2 \mathrm{NH}_{4} \mathrm{H}_{2} \mathrm{PO}_{4} \cdot\left(\mathrm{NH}_{4}\right)_{2} \mathrm{HPO}_{4}$ undergoes a phase transition at $\sim 321 \mathrm{~K}$ changing its symmetry from the centrosymmetric class $2 / \mathrm{m}$ to the polar class $\mathrm{m}$ [3]. The TAAP crystals were grown from aqueous solution at room temperature. The composition of the solution was the same as described by Nicolau [4,5]. In order to observe the domain structure we used the nematic phase of p-methoxybenzylidene-p-n-butylaniline (MBBA) and p-ethoxy-benzylidene-p-n-butylaniline (EBBA) mixture of liquid crystals (NLC). After supplying a sample (coated with NLC-layers on its surfaces) with transparent electrodes, the electric field could be applied and the observation of the domain structure was carried out using a polarizing microscope. The method for studying the domain kinetics is based on the visualization with NLC of the moving domain walls. The reversed regions, where reorientation of the domain structure still occurs, look somewhat darker than the "white" surrounding domains, since in these regions certain electrohydrodynamic instability, particularly dynamic scattering of NLC molecules, takes place [6]. It should be emphasized that the thickness of the "visible" walls is not the real physical thickness of the domain walls, which are usually very thin, of the order of a few lattice constants. 


\section{Results and discussion}

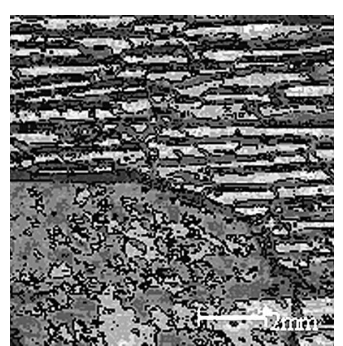

Figure 1. Domain pattern in as-grown TAAP sample at room temperature, revealed by etching with water. Polarization axis is approximately normal to the image plane (101).
Microscopic observations of the domain structure show that TAAP crystals, grown at room temperature, are highly inhomogeneous; regions may exist that exhibit switchable polarization and there are parts with more fixed polarization. Figure 1 shows the etched pattern of the domain structure observed on (101) natural face of the crystal, which is approximately normal to the polarization direction. Some part of the crystal has plate-like domains elongated in the b-direction while the other part is a single domain. The single domain state, observed in the lower part of the image in figure 1 does not vanish when heating over a transition temperature, but can still be detected at room temperature. When polarization was switched to the opposite direction it was found that this single domain region was not uniform. This can be seen by observing non-uniform distribution of domain nuclei that arise in external electric field.

For comparison, figure 2 presents the distribution of domain nuclei in various dc electric fields, observed in a more homogeneous region of the crystal sample (with plate-like domains in as-grown crystal). In weak dc fields, the plate-like domains elongated in the b-direction were observed on the crystal surface normal to the polar axis. In higher electric fields circular domains are nucleated (see figure 2(a)). When electric field increases, the new nuclei appear adjacent to the moving domain walls. We found the wall to be often of zigzag type, as a result of preferential formation of new nuclei along the b-direction (see figure 2(b), (c)). In sufficiently high electric fields, the intensive domain nucleation occurs upon the whole homogeneous fragment of the crystal sample (see figure $2(\mathrm{~d})$ ).

The domain nuclei which are randomly distributed in weak fields are aligned into nearly parallel rows (parallel to the b-direction) in higher electric fields. This indicates the importance of crystallographic factors in the ordering of defects (which are nucleation centers) in the process of crystal growth. With the increase of an electric field, the density of the domain nuclei in each row and the number of chains per unit length increase, so that they become optically indistinguishable (as is shown in figure 3 ). Figure 3 presents the distribution of domain nuclei in alternate square pulses of electric field in the region of the crystal sample in which single domain state was observed in as-grown crystal (lower part of the region in figure 1). The amplitude and frequency were so chosen that they could only permit a nucleation of domains.
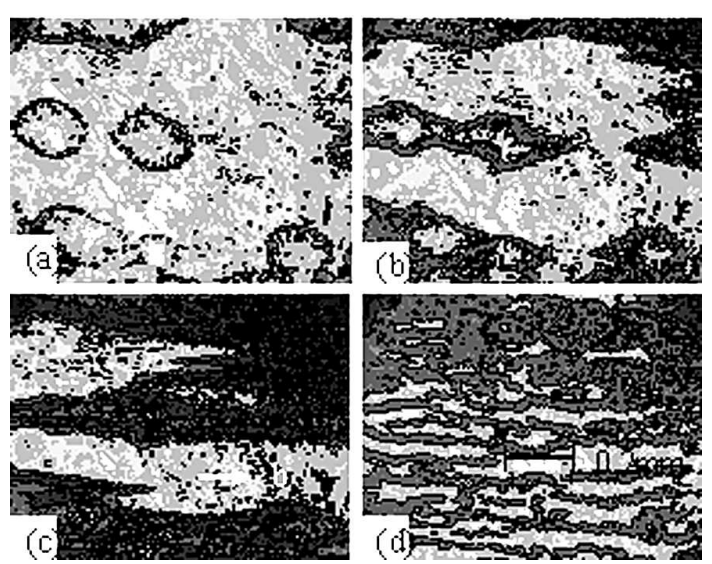

Figure 2. Domain configuration at various dc fields, observed in homogeneous region of TAAP crystal sample; (a) $125 \mathrm{kV} / \mathrm{m}$, (b) $135 \mathrm{kV} / \mathrm{m}$, (c) $145 \mathrm{kV} / \mathrm{m}$, (d) $160 \mathrm{kV} / \mathrm{m}$.

\section{It is shown that the formation of domains is} possible if the amplitude of electric field exceeds some threshold value at a given site of the crystal. There are parts in which intensive domain nucleation arranged in rows is seen, and parts where the nucleation process is suppressed. The inhomogeneous distribution of the domain nuclei is a result of non-uniform internal field distribution within the crystal sample. This can be clearly seen during the switching process in dc-electric fields. Figures 4(a)-(b) show the series of video frames illustrating the domain pattern evolution observed in a small (about $1 \mathrm{~mm}^{2}$ ) fragment of the crystal sample in a region set in frame in figure 3(a). We observed a fast partial switching, by intensive nucleation of domains arranged in rows, instantaneously after the field application in the upper part of the first image in figure 4(a). Further switching continues to occur more slowly through the new domains arising adjacent to the moving domain front, formed after coalescence of domains. The moving 
domain front goes through smoothly from one part of the crystal to another with a decreasing velocity. Very approximate estimations give values from $6 \times 10^{-4} \mathrm{~m} / \mathrm{s}$ at the initial stage to $2 \times 10^{-6}$ $\mathrm{m} / \mathrm{s}$ at the end of the switching process. In higher dc fields, the mechanism of the switching process does not change; only the region with the intensive domain nucleation becomes larger (figure 4(b)).
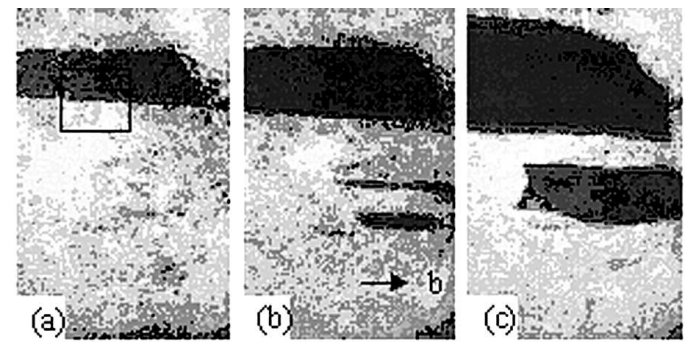

Figure 3. Distribution of domain nuclei arising in pulsed electric field at various pulse amplitudes: (a) $200 \mathrm{kV} / \mathrm{m}$, (b) $300 \mathrm{kV} / \mathrm{m}$, (c) $400 \mathrm{kV} / \mathrm{m} ; \mathrm{f}=100 \mathrm{~Hz}$. The polarization axis is approximately normal to the image plane (101). Dark regions in the images represent the sites at which the reorganization of the domain structure still occurs.

The experimental results are represented as sets of switching curves, where for each curve, the switching polarization is plotted as a function of time for the fixed electric field, as is shown in figure 5. There is observed an essential difference between the domain kinetics observed in inhomogeneous crystal samples and homogeneous ones. In a homogeneous crystal sample, the switching curves taken at different electric fields typically saturate at the same value, so that they relate to the complete polarization reversal [7]. In the examined inhomogeneous region of the crystal sample, the saturation value of the switching polarization increases with the electric field increase. This inhomogeneous crystal sample consists of independently switched regions in which polarization reversal process is limited mainly by nucleation of reversed domains.

After switching the polarization vector under an external electric field, an unstable state of polarization is created, which then relaxes to the initial single domain state after the removal of the electric field, as shown in figure 6(a). One can see that the process of spontaneous depolarization occurs in reverse order to the switching process; first nucleation of backswitching domains is observed in the lower part of the image in figure 6(a). It is interesting to note that the effective field during the spontaneous backswitching process is comprised of the sum of depolarization field due to the unscreened portion of the polarization bound charges and an internal bias field $\mathrm{E}_{\mathrm{b}}$. The fact that the spontaneous backswitching process has not been observed in the crystal sample with a symmetric switching property for positive and negative polarization state (without $\mathrm{E}_{\mathrm{b}}$ ) demonstrates that the polarization relaxation behavior should be dominated by directional internal field caused by structural disorder in the examined crystal sample.

The slowing down of the polarization relaxation process can be obtained when the external field is applied to the opposite direction of $\mathrm{E}_{\mathrm{b}}$, as shown in figure $6(\mathrm{~b})$. It means that the strong polarization relaxation could be closely related to the large $\mathrm{E}_{\mathrm{b}}$, inside the crystal sample. We could experimentally determine the approximate local value of $\mathrm{E}_{b}$ from the applied electric field under which the polarization relaxation is stopped at the given site of the crystal. Figure 7 presents the time dependence of the normalized retained polarization with respect to the initial polarization $\left.\mathrm{P}(\mathrm{t}) / \mathrm{P}_{0}\right)$ taken during the backswitching process. The value of $\mathrm{E}_{\mathrm{b}}$ is different in various regions of the crystal sample. Very approximate estimations give the values from $20 \mathrm{kV} / \mathrm{m}$ in the upper to $240 \mathrm{kV} / \mathrm{m}$

(a)
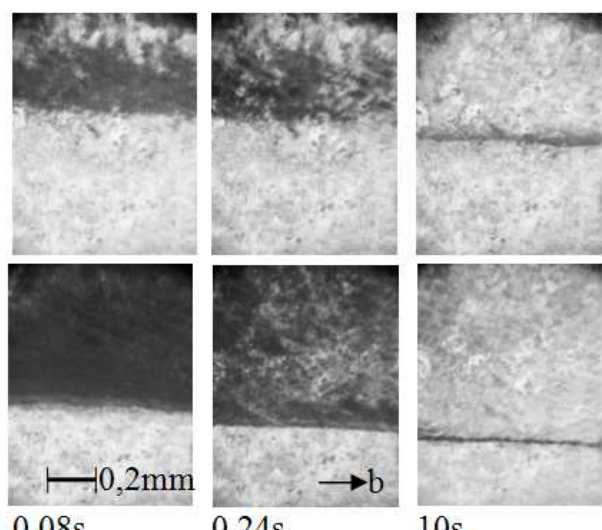

(b)
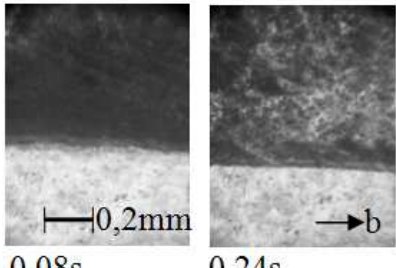

$0,24 \mathrm{~s}$
$10 \mathrm{~s}$

Figure 4. Selected video frames in recording of domain pattern evolution during the switching process at two different dc fields: (a) $200 \mathrm{kV} / \mathrm{m}$, (b) $300 \mathrm{kV} / \mathrm{m}$. in the lower region of the image in figure 6 . 
Figure 5. Temporal dependence of the switched area for various electric fields (calculated for domain configurations, as shown in Fig. 4).

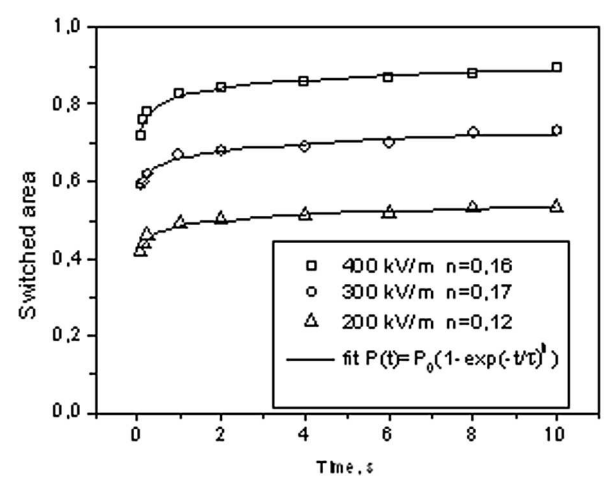

The relaxation of polarization during the switching process as well as during spontaneous backswitching process is well described by a Kohlrausch-Williams-Watts (KWW) stretched exponential function $P(t)=P_{0} \exp (-t / \tau)^{n}$ with $0<$ $n<1$. KWW function has been widely used in the dielectric relaxation studies [8]. The existing literature is not consistent regarding their origin and explanations. Theories based on the defect distribution in disordered systems or on the distribution of relaxation times have been developed [9].

On analyzing the switching process in a homogeneous crystal sample [7], the kinetics of polarization switching in external electric field has been well described by the Avrami function i.e., the expression of the same form as KWW function, with exponential coefficient ranging from 1 to 2 . In that case the exponential coefficient could express the spatial dimensionality of the domain growth, which should take the integer value of 2 for two-dimensional domain growth (circular domains as shown in figure 2(a)) and the value of 1 for one-dimensional domain growth (as shown in figure 4). The data analysis has revealed no integer dimensionality of the domain growth, contrary to expectations from the Avrami equation, due to the dependence of the rate of growth of particular domain on the state of the crystal (i e. impurities, defects, etc). The Avrami model is a simplification of the real physical conditions assuming a constant domain growth velocity. (a)

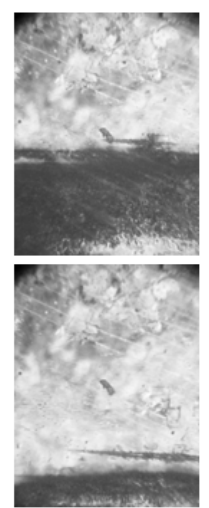

$0,08 \mathrm{~s}$

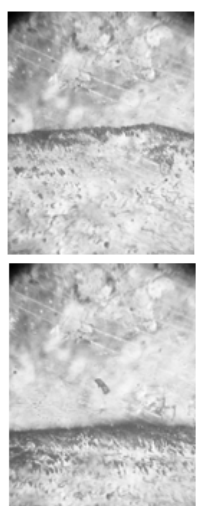

$0,48 \mathrm{~s}$

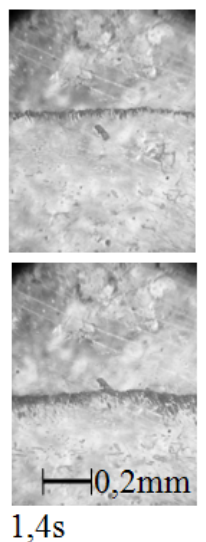

$1,4 \mathrm{~s}$
Figure 6. Selected video frames in recoding of domain pattern evolution during the backswitching process at: (a) $\mathrm{E}=0$, (b) $\mathrm{E}=30 \mathrm{kV} / \mathrm{m}$ applied in the direction opposite to $\mathrm{E}_{\mathrm{b}}$.

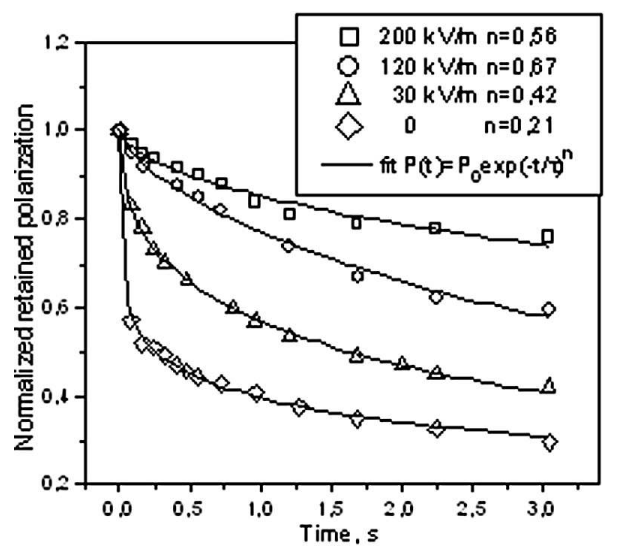

Figure 7. Slowing down of the domain relaxation at the external electric fields applied in the direction opposite to $\mathrm{E}_{\mathrm{b}}$.

We have shown that the main peculiarities of the non-uniform ferroelectrics are the presence of an in-built internal field and a broad distribution function for the random field. Hence, we observe a broad distribution of characteristic domain growth times. Generally, substitutional disorder, vacancies, and displacement of ions from their equilibrium positions create random fields [10, 11]. In disordered ferroelectric systems, the defects locally modify the depths of the double-well potential giving rise to spatially varying energy barriers for domain nucleation. Now it is hard to explain what kind of crystal imperfections or non-uniformities are responsible for stabilization effects and the broad spectrum of potential barriers for the domain nucleation in TAAP crystals. The examined crystal sample was obtained from a non-stoichiometric solution. During the crystal 
growth the defects are built in a preferential alignment. The above results suggest that the defects can induce a space charge gradient, which in turn generates an internal bias field, causing the observed preferential orientation of polarization.

\title{
4. Conclusions
}

Imaging measurements confirm the site-specific nature of nucleation of domains in TAAP crystals. The defects present in the crystal sample seem to play the major role in creating an internal bias field causing the observed preferential orientation of polarization, making the poling procedure impracticable. Stretched exponential polarization relaxation is observed in highly inhomogeneous crystals, in which domain wall propagates at a decreasing rate at a spatially inhomogeneous, gradually decreasing internal field. The use of NLC method should offer a relatively simple and rapid means of quality control in determining the degree of domain alignment in ferroelectric crystals.

\section{Acknowledgements}

The authors would like to thank Prof. Z. Czapla from University of Wroclaw for providing TAAP samples for this study.

\section{References}

1. Ishibashi Y., Takagi Y. J. Phys. Soc. Jpn, 1971, 31, 506.

2. Guo H.Y., Xu J.B., Xie Z., Luo E.Z., Wilson I.H., Zhong W.L. Solid State Commun., 2002, 121, 603.

3. Guillot Gauthier S, Peuzin J. C., Olivier M, Rolland G. 1984 Ferroelectrics 52, 293.

4. Nicolau Y.F. Ferroelectrics, 1984, 52, 281.

5. Przeslawski J., Kosturek B., Czapla Z., Tomaszewski P.E., Wondre F. Ferroelectrics, 1994, 152, 255.

6. Tikhomirova N.A., Dontsova L.I., Pikin S.A., Shuvalov L.A. JETP Lett., 1979, 29, 34.

7. Matyjasek K., Rogowski R.Z. J. Phys. Condens. Matter, 2006, 18, 7687.

8. Kim K., Epstein A.J. Appl. Phys. Lett., 1995, 67, 2786.

9. Scher H., Shlesinger M.F., Bendler J.T. Phys. Today, 1991, 44, 26.

10. Glinchuk M.D., Stephanovich V.A. J. Appl. Phys., 1999, 85, 1722.

11. Gopalan V., Mitchell T., Furukava Y., Kitamura K. Appl. Phys. Lett., 1998, 72, 1981.

\section{Динаміка доменної структури у неоднорідних сегнетоелектричних кристалах}

\author{
К.Матиясек, Р.Роговскі \\ Інститут фізики, Щецінський технологічний університет, ал. П'ястув, 48, 70-310 Щецін, Польща \\ Отримано 4 вересня 2006 р.
}

Дана робота представляє дослідження властивостей оборотних процесів у доменах, пов'язаних 3 внутрішнім полем зміщення у неоднорідних кристалах телуровокислого сульфату амонію. Нами показано, що існує прямий зв'язок між дефектною структурою цього кристалу із затягнутою експоненційною релаксацією поляризації у сегнетоелектричних кристалах. Перемикання доменів вивчалось з використанням технології нанесення нематичних рідких кристалів.

Ключові слова: сегнетоелектричні домени, переключення поляризації, внутрішнє поле зміщення

PACS: $77.80 . D j, 77.80 . F m, 77.84$ 
